ARTICLE

DOI: $10.1038 / \mathrm{s} 41467-017-02714-7$

\title{
Detecting RNA base methylations in single cells by in situ hybridization
}

Rohan T. Ranasinghe (1) ${ }^{1}$, Martin R. Challand (10 ${ }^{2,4}$, Kristina A. Ganzinger (1) ${ }^{1,5}$, Benjamin W. Lewis (1) ${ }^{1}$ Charlotte Softley ${ }^{1}$, Wolfgang H. Schmied ${ }^{3}$, Mathew H. Horrocks ${ }^{1}$, Nadia Shivji', Jason W. Chin (1) ${ }^{1,3}$, James Spencer ${ }^{2} \&$ David Klenerman ${ }^{1}$

Methylated bases in tRNA, rRNA and mRNA control a variety of cellular processes, including protein synthesis, antimicrobial resistance and gene expression. Currently, bulk methods that report the average methylation state of $\sim 10^{4}-10^{7}$ cells are used to detect these modifications, obscuring potentially important biological information. Here, we use in situ hybridization of Molecular Beacons for single-cell detection of three methylations $\left(m^{6}{ }_{2} A, m^{1} G\right.$ and $\left.m^{3} U\right)$ that destabilize Watson-Crick base pairs. Our method-methylation-sensitive RNA fluorescence in situ hybridization-detects single methylations of rRNA, quantifies antibiotic-resistant bacteria in mixtures of cells and simultaneously detects multiple methylations using multicolor fluorescence imaging.

\footnotetext{
${ }^{1}$ Department of Chemistry, University of Cambridge, Lensfield Road, Cambridge CB2 1EW, UK. ${ }^{2}$ School of Cellular and Molecular Medicine, University of Bristol, Bristol BS8 1TD, UK. ${ }^{3}$ Medical Research Council Laboratory of Molecular Biology, Francis Crick Avenue, Cambridge CB2 OQH, UK. ${ }^{4}$ Present address: School of Biochemistry, University of Bristol, Bristol BS8 1TD, UK. ${ }^{5}$ Present address: Max-Planck-Institut für Biochemie (MPI for Biochemistry), 82152 Martinsried, Germany. Correspondence and requests for materials should be addressed to

R.T.R. (email: rr360@cam.ac.uk) or to M.R.C. (email: Martin.Challand@bristol.ac.uk)
} 
$\mathrm{t}$ is becoming increasingly clear that methylated RNA bases play key roles in all forms of life. It has been known for over 50 years that ribosomal RNA (rRNA) contains methylated bases ${ }^{1}$ : 21 of the 35 post-transcriptional modifications to the Escherichia coli ribosome include base methylations ${ }^{2}$, while 8 other methylated bases confer antibiotic resistance by preventing binding of protein synthesis inhibitors ${ }^{3}$. For example, the rRNA methylations catalyzed by Erm (forming $N^{6}$-dimethyladenosine, $\left.\mathrm{m}_{2}^{6} \mathrm{~A}\right)^{4}$ and Cfr (forming 2,8-dimethyladenosine, $\left.\mathrm{m}^{2,8} \mathrm{~A}\right)^{5}$ both render bacteria multi-drug resistant. Among the numerous modifications to transfer RNA (tRNA), 1-methylguanosine $\left(\mathrm{m}^{1} \mathrm{G}\right)$ at position 37, which minimizes frameshift mutations during protein synthesis $^{6}$, is notable for being conserved across all kingdoms of life. The observations that the fat mass and obesity-associated (FTO) protein demethylates $N^{6}$-methyladenosine $\left(\mathrm{m}^{6} \mathrm{~A}\right), 3$ methyluridine $\left(\mathrm{m}^{3} \mathrm{U}\right)$ and 3-methylthymidine $\left(\mathrm{m}^{3} \mathrm{~T}\right)$ in singlestranded $\mathrm{RNA}^{7,8}$ led to the realization that eukaryotic messenger RNAs (mRNAs) undergo dynamic and widespread methylations at N6 and N1 of adenine ${ }^{9-13}$, which likely regulate expression. This flurry of recent discoveries has refocused attention on posttranscriptional RNA modifications ${ }^{14}$, and spawned a new field: epitranscriptomics.

The epitranscriptome lay underappreciated until the last 5-10 years because methods for detecting methylated bases were unsuitable for studying mRNA. Conventionally, cellular RNAs are digested to individual nucleosides that are separated by liquid chromatography to identify modified bases, which are then put into sequence context by a separate reverse transcription assay, analyzed using gel electrophoresis ${ }^{15}$. These bulk methods have detection limits in the femtomole to picomole range, which even for abundant species like rRNAs therefore report the average methylation state of $\sim 10^{4}-10^{7}$ cells ${ }^{16}$. Even state-of-the-art methods for mapping modified bases-based on immunoprecipitation followed by next-generation sequencing-pool the lysates from $>10^{4}$ cells $^{17}$. In contrast, microscopy-based fluorescence in situ hybridization (FISH) ${ }^{18}$ is revolutionizing transcription profiling by capturing cell-to-cell variation in mRNA levels ${ }^{19}$, and revealing the sub-cellular distributions of specific mRNAs on the basis of their unique nucleotide sequences ${ }^{20}$. In situ hybridization techniques capable of detecting methylated bases within specific RNAs could be similarly illuminating, greatly enhancing our understanding of the biological roles of individual methylations.

Here, we use in situ hybridization to detect epitranscriptomic modifications at the single-cell level, exploiting the fact that methyl groups on the Watson-Crick faces can impair base pairing 21,22 . Our approach deploys hybridization probes that are sensitive to methylation of their complementary RNA sequences as intracellular thermodynamic sensors. We call this method "methylation-sensitive RNA fluorescence in situ hybridization" (MR-FISH), which we validate in a series of methyltransferaseknockout bacterial cell lines, focusing on rRNA methylations. MR-FISH is sensitive to single methylations, and can characterize the composition of heterogeneous mixtures of cells that differ only in RNA methylation.

\section{Results}

Detecting tetramethylation by KsgA methyltransferase. In designing a hybridization assay for methylation, we selected Molecular Beacons (Supplementary Fig. 2) ${ }^{23}$. We reasoned that these hybridization probes, which discriminate single-base changes better than linear probes because they can form a hairpin structure rather than bind to a mismatched nucleic acid ${ }^{24}$, might also be sensitive to methylation of a complementary nucleic acid. We first tested whether a Molecular Beacon could detect the tetramethylation catalyzed by the methyltransferase (MTase) KsgA (Fig. 1a), one of the best-studied post-transcriptional modifications of rRNA. KsgA dimethylates A1518 and A1519 of $16 \mathrm{~S}$ rRNA to form consecutive $\mathrm{m}^{6}{ }_{2} \mathrm{~A}$ bases, subtly restructuring the $30 \mathrm{~S}$ subunit of the ribosome; ${ }^{25}$ bacteria that lack this modification are resistant to the aminoglycoside antibiotic, kasugamycin ${ }^{26}$. Because the three states of Molecular Beacons (hairpin structure, hybridized to the target and random coil) have different fluorescence intensities due to changes in the fluorophore-quencher distance (Supplementary Fig. 2), the stability of duplexes they form with different target sequences can be measured by monitoring fluorescence during thermal melting. This technique verified that a Molecular Beacon designed to detect methylation by KsgA shows a transition for melting of an RNA/DNA duplex with complementary unmethylated RNA, but only a transition for melting of the hairpin loop in the presence of tetramethylated RNA (Fig. 1c). This indicates that the impaired base pairing of adjacent $\mathrm{m}^{6}{ }_{2} \mathrm{~A}$ nucleotides (Fig. 1b) inhibits the binding of the methylation-sensitive probe.

To detect post-transcriptional modifications inside fixed cells, we use two probes: a green-fluorescent (Alexa Fluor 488-labeled) methylation-sensitive probe and a red-fluorescent (Alexa Fluor 647-labeled) probe that binds the same rRNA strand, at a sequence remote from the modification site that does not undergo methylation. This red-labeled methylation-insensitive probe acts as an internal calibrant, meaning that the red/green ratio of each cell-rather than the green intensity alone-indicates the extent of methylation. This ratio distinguishes between cells with a high proportion of methylated rRNA and cells which simply have a low concentration of rRNA (Fig. 1d). To investigate whether MRFISH distinguishes between cells with highly methylated and unmethylated ribosomes, we used an E. coli which expresses all constitutive rRNA MTases (parent strain BW25113), and a mutant of this strain in which the KsgA MTase is deleted $(\Delta k s g A)$, confirming the methylation state of each cell type by high-performance liquid chromatography (HPLC; Supplementary Fig. 3). Both bacteria fluoresce red due to the methylationinsensitive probe, but only the $\Delta k s g A$ cells, with A1518 and A1519 of $16 \mathrm{~S}$ rRNA unmethylated, are brightly stained green by the methylation-sensitive probe (Fig. 1e). Automated analysis of the wide-field epifluorescence images (Methods, Supplementary Fig. 4) allows us to extract fluorescence intensities of hundreds of single cells in both color channels, which quantitatively confirms that MR-FISH distinguishes between cells with methylated and unmethylated ribosomes (Fig. 1f). Timecourses of hybridization show that $\Delta k s g A$ cells can be distinguished from the parent strain after $30 \mathrm{~min}$, but that they are best discriminated after $\geq 4.5 \mathrm{~h}$, when the ratio of their green fluorescence intensities is $>10$ (Supplementary Fig. 5). The fluorescence of the methylationsensitive probe is selectively reduced in the presence of excess unlabeled oligonucleotide with the same sequence, confirming that the signal results primarily from hybridization, rather than non-specific binding to cellular components or autofluorescence (Supplementary Fig. 10). When the red/green ratios of individual cells are extracted from MR-FISH image data, each cell type displays a log-normal distribution (Fig. 1g and Supplementary Fig. 6), which unambiguously discriminates between cells with tetramethylated and unmethylated ribosomes in replicate measurements (Fig. 1h and Supplementary Fig. 7).

MR-FISH is sensitive to single methylations. We then challenged MR-FISH to detect single methylations of rRNA using the same parent strain and two additional mutants, from which two other constitutive MTases are deleted: RrmA and RsmE, which respectively catalyze introduction of 1-methylguanine $\left(\mathrm{m}^{1} \mathrm{G}\right)$ at G745 in $23 \mathrm{~S}$ rRNA $^{27}$, and 3-methyluridine $\left(\mathrm{m}^{3} \mathrm{U}\right)$ at U1498 in 
a

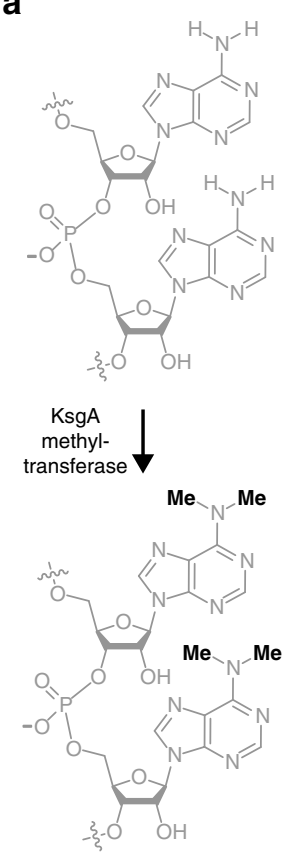

f

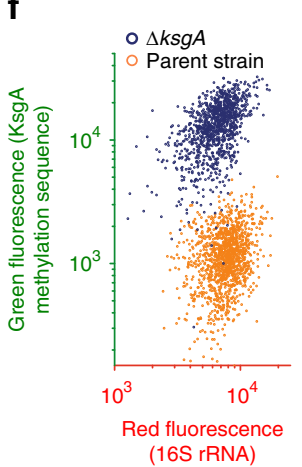

b

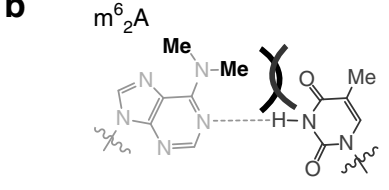

c
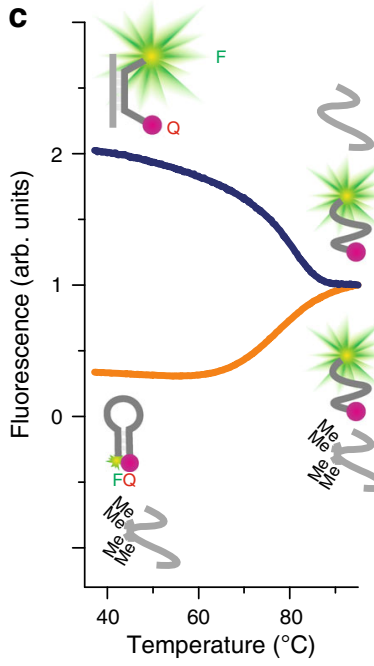

g
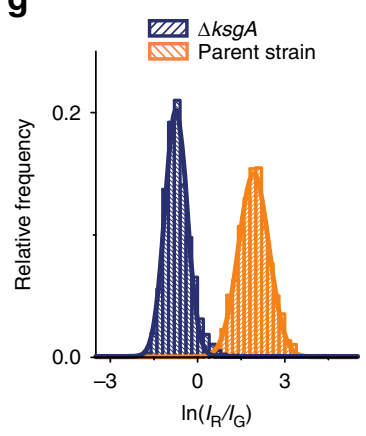

d

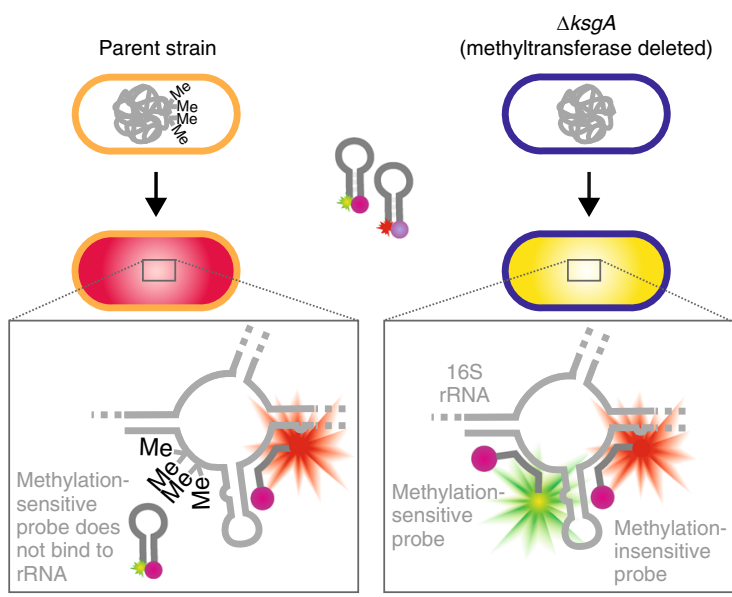

e
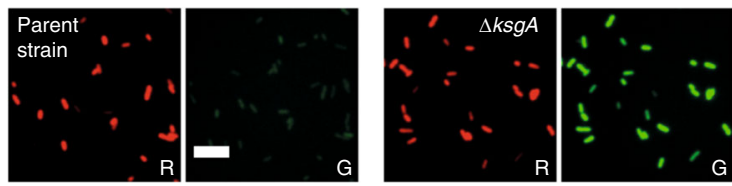

h

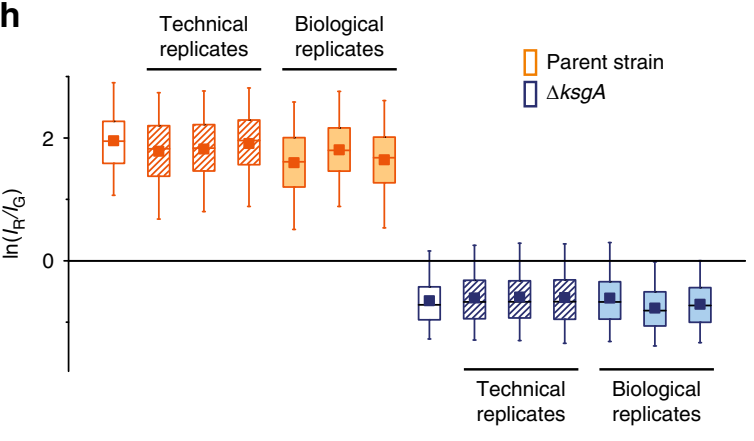

Fig. 1 Destabilized base pairing by methylated RNA enables detection of post-transcriptional modification in single cells. a $N^{6}$-Dimethylation of $A 1518$ and A1519 in $16 \mathrm{~S}$ rRNA catalyzed by KsgA. b $N^{6}$-Dimethyladenine $\left(\mathrm{m}_{2}^{6} \mathrm{~A}\right)$ is sterically inhibited from base pairing with thymine. c A Molecular Beacon can discriminate between methylated and unmethylated synthetic RNA, as revealed by in vitro thermal melting. d MR-FISH assay for rRNA methylation, using two Molecular Beacons and two strains of E. coli:, one expressing active KsgA (parent strain) and one mutant strain with the methyltransferase deleted from its genome $(\Delta k s g A)$. e Fluorescence images showing that $\Delta k s g A E$. coli are stained red and green by MR-FISH probes, while parent strain cells are brightly stained only by the methylation-insensitive red probe. Scale bar: $10 \mu \mathrm{m}$. f Scatter plots of red and green fluorescence intensities of parent strain ( $n$ $=1315$ cells $)$ and $\Delta \mathrm{ksgA}\left(n=1112\right.$ cells) bacteria stained by MR-FISH. $\mathbf{g}$ Log-normally distributed ratios of red fluorescence intensity $\left(I_{R}\right)$ to green fluorescence intensity $\left(I_{\mathrm{G}}\right)$ of bacteria stained by MR-FISH. h Box plots (box: 25th-75th percentiles; whiskers: 5th-95th percentiles; horizontal line: medians; squares: means) of two-color ratios shown in (g) (empty bars), as well as technical replicates (hatched bars) and biological replicates (filled bars). From left to right, $n=1315,1056,1173,1115,865,1253,927,1110,1291,1523,1374,1118,850$ and 988 cells per sample

$16 \mathrm{~S} \mathrm{rRNA}^{28}$. Methylation-sensitive probes for each modification discriminate well between methylated and unmethylated synthetic RNAs, but unlike the tetramethylated KsgA target sequence, fluorescence melting showed evidence of duplex formation between both methylation-sensitive beacons and their singly methylated RrmA and RsmE target sequences (Fig. 2a, b). The duplex formed by the RsmE target containing a single $\mathrm{m}^{3} \mathrm{U}$ base was stable enough to thermodynamically characterize, showing it to be destabilized by $\sim 20 \mathrm{~kJ} \mathrm{~mol}^{-1}$ compared with its unmethylated counterpart, which decreases its melting temperature by $\sim 17^{\circ} \mathrm{C}$ (Supplementary Fig. 2). Nevertheless, MR-FISH detected both methylated bases inside fixed cells, although a higher formamide concentration ( $30 \%$ vs. $20 \%$ ) was required to discriminate the less-destabilizing $\mathrm{m}^{3} \mathrm{U}$ modification (Fig. 2c-f, Supplementary Figs 8 and 9). These data show that MR-FISH can detect even single methylations of RNA.
Characterizing mixtures of cells with different methylation states. A major advantage of detecting epitranscriptomic modifications on a cell-by-cell basis, rather than in lysates pooled from thousands or millions of cells, is the potential to study heterogeneous populations without separating them first. To demonstrate this concept, we used MR-FISH to characterize the composition of mixtures of $E$. coli and the kasugamycin-resistant derivative $\Delta k s g A$. We first combined different ratios of separately cultured samples of each strain and analyzed the mixtures using MR-FISH. Fitting the resulting two-color-ratio histograms with bimodal Gaussian distributions returns compositions that are in excellent agreement with the known proportions of parent strain and $\Delta k s g A$ cells (Fig. $3 \mathrm{a}-\mathrm{c}$ ). Next, we measured the composition of a co-culture of these bacteria using MR-FISH, which was in good agreement with that determined by colony counting (Fig. 3d-g). The greater precision of our single-cell approach- 

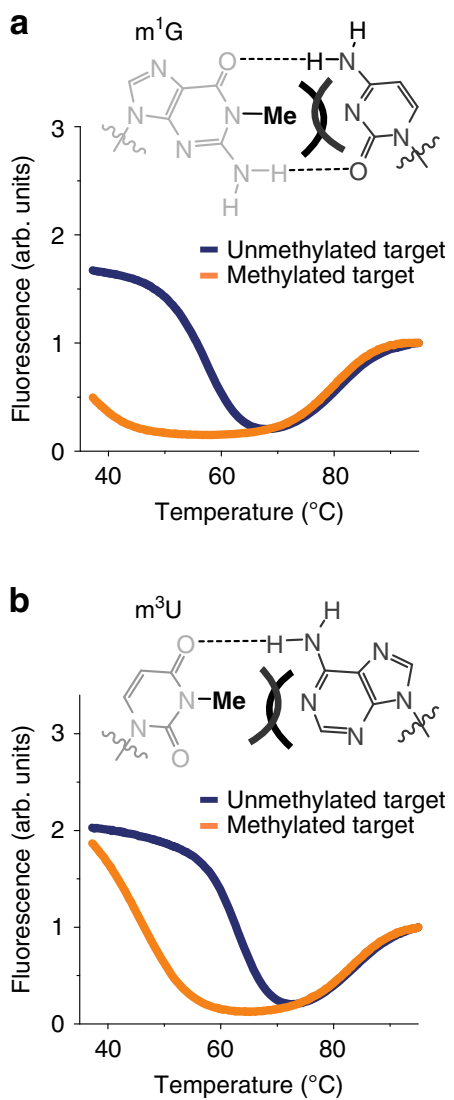

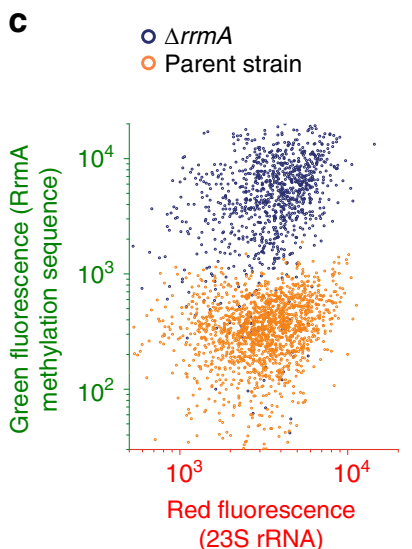

d

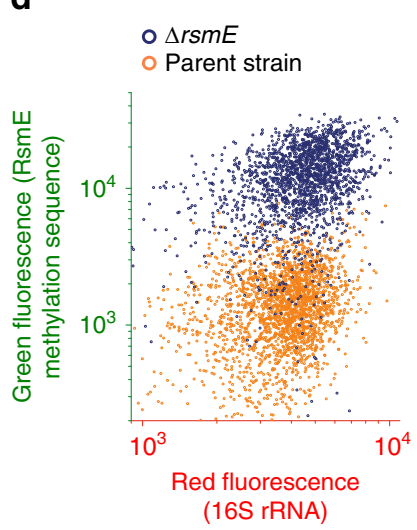

e

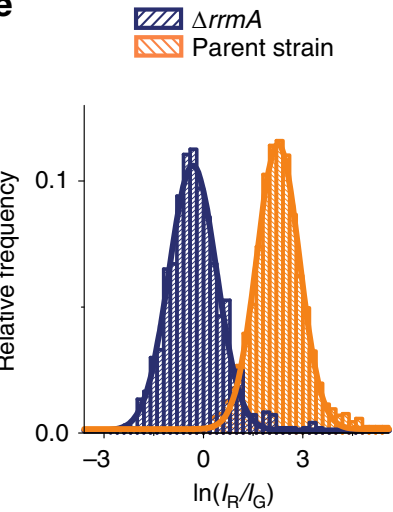

f

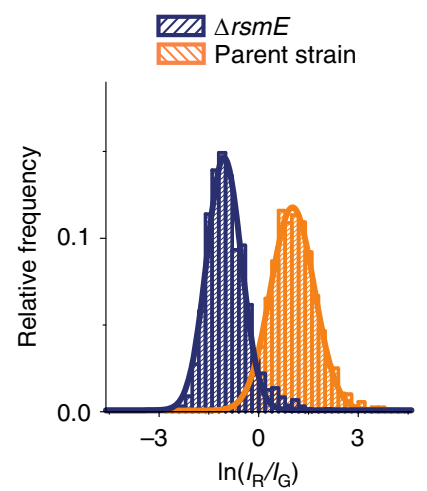

Fig. 2 MR-FISH can detect single methylated $\mathrm{m}^{1} \mathrm{G}$ and $\mathrm{m}^{3} \mathrm{U}$ bases. Discrimination by Molecular Beacons between methylated and unmethylated synthetic RNA target sequences of $\mathbf{a}$ RrmA and $\mathbf{b}$ RsmE. Scatter plots of red and green fluorescence intensities of bacteria stained by MR-FISH using hybridization probes for RrmA (c; $n=1567$ (parent strain) and $966(\Delta r r m A)$ cells) and RsmE (d; $n=2266$ (parent strain) and 1894 ( $\Delta r s m E$ ) cells) modifications. Lognormally distributed ratios of red fluorescence intensity $\left(I_{R}\right)$ to green fluorescence intensity $\left(I_{G}\right)$ of bacteria stained by MR-FISH using hybridization probes for e RrmA and $\mathbf{f} \operatorname{RsmE}$

reflected in the smaller standard deviation of the measured fraction (Fig. 3g) -is in line with that expected from Poisson statistics, because $450-850$ cells are counted per measurement compared with 25-100 colonies.

Finally, we combined methylation-sensitive Molecular Beacons to demonstrate simultaneous detection of two methylations using multicolor imaging (Fig. 4). We multiplexed MR-FISH using a probe cocktail comprising an Alexa-Fluor-647-labeled-methylation-insensitive probe, an Alexa-Fluor-488-labeled probe sensitive to KsgA methylation and a Cy3-labeled probe sensitive to RrmA methylation (Fig. 4a). A mixture of bacteria containing either of these methylations $(\triangle k s g A$ or $\Delta r r m A)$ or both methylations (parent strain) are therefore stained with different color combinations: either Alexa Fluor 647 and Alexa Fluor 488 $(\Delta k s g A)$, Alexa Fluor 647 and Cy3 $(\Delta r r m A)$, or Alexa Fluor 647 only (parent strain) (Fig. 4b). Comparison to pure samples of each bacterium confirms that MR-FISH can accurately identify the components of a complex mixture of bacteria with multiple different methylation states (Fig. 4c, d and Supplementary Fig. 11).

\section{Discussion}

This work demonstrates the detection of methylated bases in RNA at the single-cell level. MR-FISH is sensitive to single methylations, and can characterize the composition of mixtures of cells with different RNA methylation states. Our results show excellent discrimination between cells with and without specific methylations; further studies will establish the sensitivity of MRFISH to different degrees of methylation. Three different methylations have been detected here, but in its current form, our hybridization-based approach will not be applicable to modifications that do not affect Watson-Crick base pairing, such as 5methylcytidine $\left(\mathrm{m}^{5} \mathrm{C}\right)$ or pseudouridine. On the other hand, $\mathrm{m}^{1} \mathrm{~A}$ has recently been shown to substantially disrupt RNA duplexes ${ }^{29}$, while $\mathrm{m}^{6} \mathrm{~A}$ forms a "spring-loaded" base pair containing a steric clash between the N6-methyl group and $\mathrm{N}^{22}$. Encouragingly, we have confirmed that the presence of $\mathrm{m}^{6} \mathrm{~A}$ does destabilize duplex formation with a Molecular Beacon, but to a lesser degree than the other modifications detected here (Supplementary Fig. 12).

The fact that standard epifluorescence microscopes can be used to detect methylation of abundant RNAs (Supplementary Fig. 13) as well as its simplicity (Supplementary Fig. 14) makes MR-FISH accessible to wide range of users. For example, our method could enable basic research into antibiotic resistance conferred by methylated bases in single or mixed bacterial populations. In particular, MR-FISH could reveal the extent of methylation needed for resistance and stochastic cell-to-cell variation within resistant populations, as well as offering a way to screen methyltransferase inhibitors inside cells with a molecular readout. The fact that MR-FISH requires simple optical equipment, is capable of multiplexing and can identify specific rRNA methylations in cells after only $30 \mathrm{~min}$ also highlights its potential in diagnostic tests for antibiotic-resistant bacteria. In future applications, the abundance of the RNA of interest will determine the most appropriate imaging mode. In exponentially growing 
a

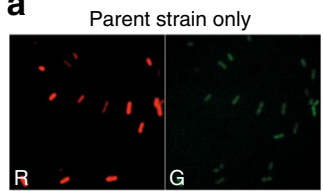

$20 \% \Delta k s g A / 80 \%$ Parent strain
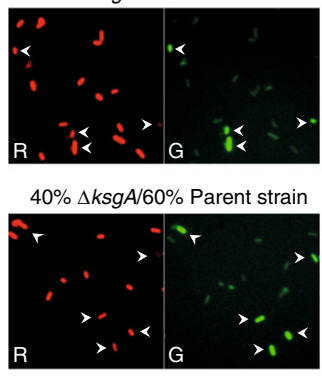

$60 \% \Delta k s g A / 40 \%$ Parent strain

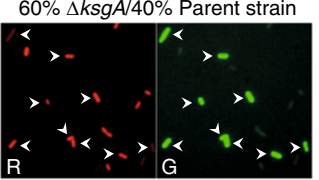

$80 \% \Delta k s g A / 20 \%$ Parent strain
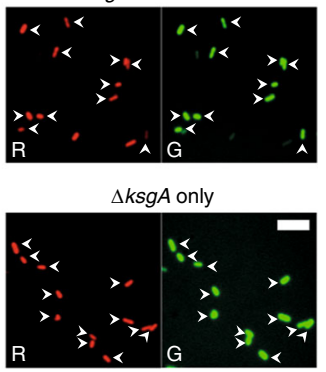

b
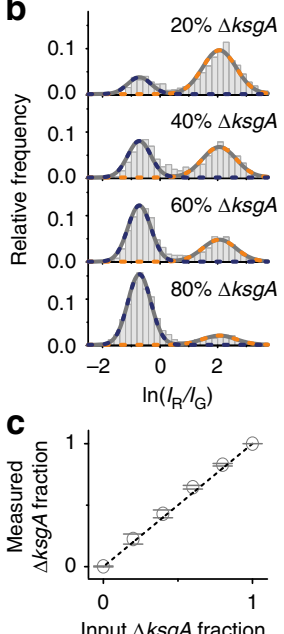

d
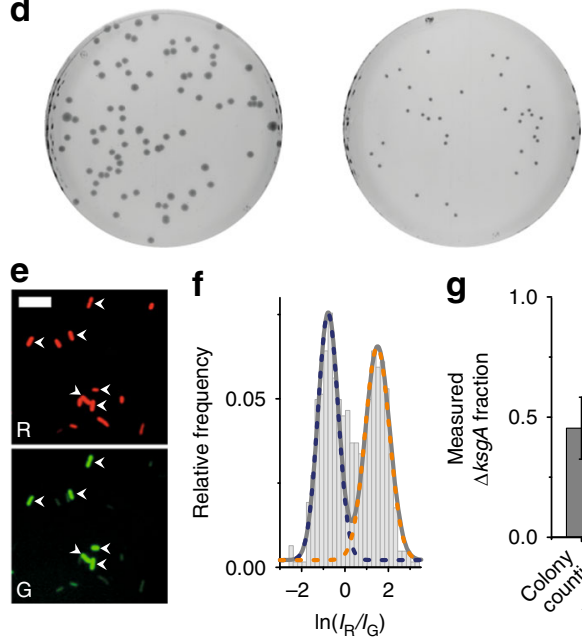

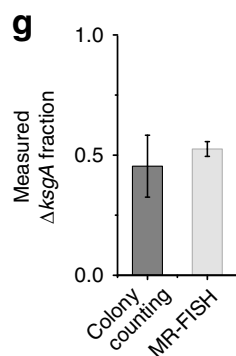

Fig. 3 Detecting heterogeneity in mixtures of bacteria with different rRNA methylation status. a False-colored red and green fluorescence images of pure samples and mixtures of parent strain and $\Delta \mathrm{ksgA}$. coli after MR-FISH. All red images are shown at one fixed brightness and contrast, and all green images at another fixed brightness and contrast. To guide the eye, manually selected bacteria with high green fluorescence intensity are indicated with arrows in both red and green images. Scale bar: $10 \mu \mathrm{m}$. b Histograms of two-color ratios obtained from mixtures of parent strain and $\Delta \mathrm{ksg} A$ bacteria $(n=1372,1639$, 1593 and 1183 cells respectively for $20 \%, 40 \%, 60 \%$ and $80 \% \Delta k s g A$ ). The data are fitted to a bimodal Gaussian distribution with centers and widths defined by fits of MR-FISH data from pure samples of each bacterium. c Quantification of the fraction of $\Delta k s g A E$. coli in mixtures with parent strain bacteria, based on the areas of each population extracted from the bimodal distributions of two-color ratios. The means and standard deviations of three technical replicates are plotted, while the equation of the dotted line is "measured fraction=input fraction". d Growth of co-culture of parent strain and $\Delta k s g A E$. coli on an agar plate (left) and a plate containing kanamycin (right), which selects for $\Delta k s g A E$. coli only. e False-colored red and green fluorescence images of co-culture after MR-FISH. Scale bar: $10 \mu \mathrm{m}$. $\mathbf{f}$ Histogram of two-color ratios of the co-culture ( $n=625$ cells), fitted to a bimodal Gaussian distribution with centers and widths defined as in (b). $\mathbf{g}$ Comparison of the fraction of $\Delta \mathrm{ksgA}$. coli in co-culture as measured by colony counting and MR-FISH. The means and standard deviations from each technique are plotted ( $n=5$ technical replicates)

a

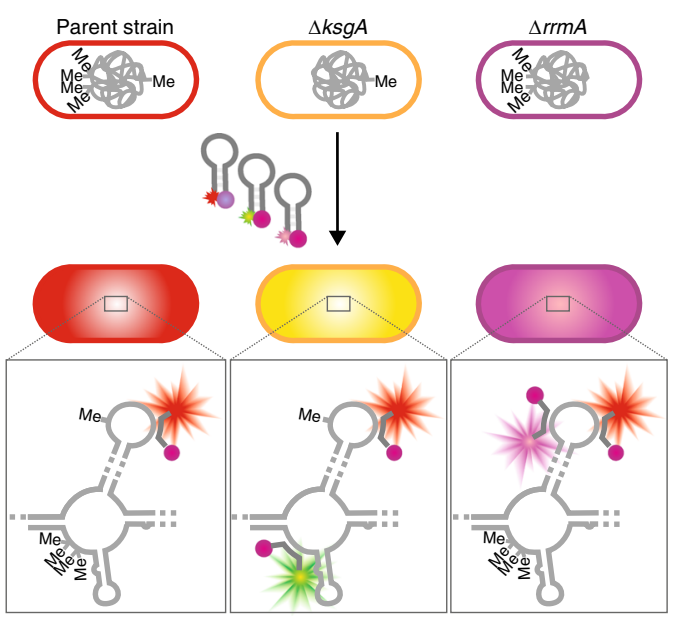

b

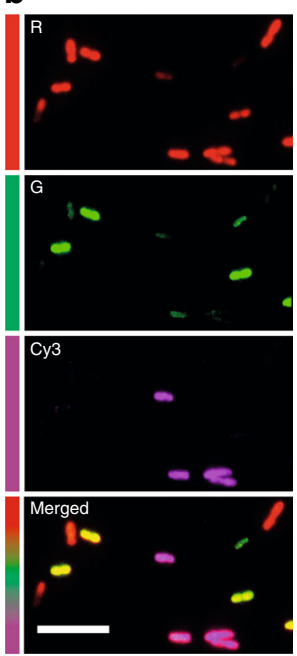

C

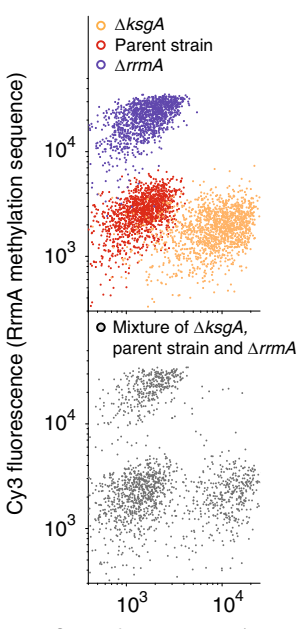

Green fluorescence (KsgA methylation sequence) d

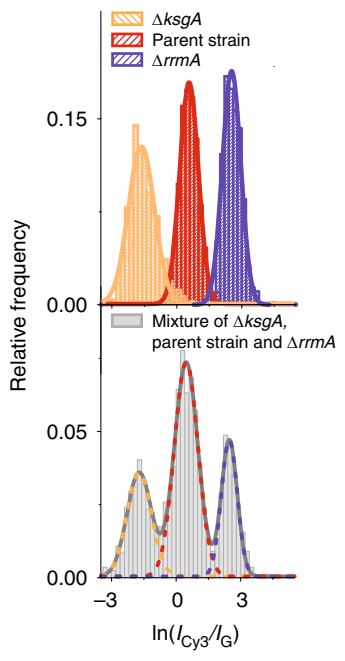

Fig. 4 Multiplexed detection of rRNA methylations with MR-FISH. a Multiplexed assay for two rRNA methylations, using three Molecular Beacons, staining an unmethylated portion of the 23S rRNA (Alexa Fluor 647-labeled), the KsgA methylation sequence (Alexa Fluor 488-labeled) and the RrmA methylation sequence (Cy3-labeled). Three strains of $E$. coli are used: one expressing active KsgA and RrmA (parent strain), one mutant strain with the KsgA methyltransferase deleted from its genome $(\Delta k s g A)$ and another mutant strain with the RrmA methyltransferase deleted from its genome $(\Delta r r m A)$. $\mathbf{b}$ False-colored fluorescence images of a mixture of parent strain, $\Delta \mathrm{ksg} A$ and $\Delta r \mathrm{rmA}$ E. coli stained with the cocktail of Molecular Beacons. Scale bar: $10 \mu \mathrm{m}$. $\mathbf{c}$ Scatter plots of green and Cy3 fluorescence intensities of parent strain ( $n=1362$ cells), $\Delta \operatorname{ksgA}(n=1411$ cells) and $\Delta$ rrmA ( $n=1288$ cells) bacteria assayed separately and in a mixture $(n=1659$ cells $)$. d Log-normally distributed ratios of Cy3 fluorescence intensity $\left(I_{\text {Cy }}\right)$ to green fluorescence intensity $\left(I_{\mathrm{G}}\right)$ of bacteria stained by MR-FISH in (c)

bacteria as measured here, rRNAs are present at $\sim 50,000$ copies/ cell $(\sim 50 \mu \mathrm{M})^{30}$, which enables single-cell measurements with epifluorescence microscopy. Individual bacterial tRNAs are present at concentrations of $1-30 \mu \mathrm{M}^{31}$, so should be detectable in the same way. At the other end of the scale, detecting any specific endogenous mRNA-typically present at $<1-30$ copies per eukaryotic cell ${ }^{32,33}$ —inherently requires single-molecule implementation of MR-FISH, which could be used to investigate 
Table 1 Sequences of synthetic oligonucleotides

\section{Code name}

RNAs

KsgA UM

KsgA Me

RrmA UM

RrmA Me

RsmE UM

RsmE Me

RImJ UM

RImJ Me

DNAs

KsgA MB

RrmA MB

RrmA MB-Cy3

RsmE MB

RImJ MB

16S MB

$16 S$ MB-G

23S MB

KsgA BLK

RrmA BLK

RsmE BLK

HLP1

HLP2

HLP3

HLP4
Sequence $\left(5^{\prime}-3^{\prime}\right)$

\author{
GUAACCGUAGGGGAACCUGCGGUUGGAUCAC \\ GUAACCGUAGGGGm $\mathbf{m}^{\mathbf{6}}{ }_{\mathbf{2}} \mathbf{A m}^{\mathbf{6}}{ }_{\mathbf{2}}$ ACCUGCGGUUGGAUCAC \\ GAACCGACUAAUGUUGAAAAAUUAGCG \\ GAACCGACUAAU $\boldsymbol{m}^{\mathbf{1}} \mathbf{G} U U \mathrm{GAAAAAUUAGCG}$ \\ GGGUGAAGUCGUAACAAGGUAACCG \\ GGGUGAAGUCG $\boldsymbol{m}^{\mathbf{3}} \boldsymbol{U} A A C A A G G U A A C C G$ \\ UUGAACUCGCUGUGAAGAUGCAGUGUACCCG \\ UUGAACUCGCUGUG $\boldsymbol{m}^{\mathbf{6}} \mathbf{A} A G A \cup G C A G U G U A C C C G$
}

\author{
Alexa Fluor 488-CCGCCCCGCAGGTTCCCCTACGGCGG-DABCYL \\ Alexa Fluor 488-CCGCCGTTTTTCAACATTAGT $\overline{C G G C G G-D A B C Y L}$ \\ Cy3-CCGCCGTTTTTCAACATTAGTCGGCGG-BHQ2 \\ Alexa Fluor 488-CGCGCCTTGTTA $\overline{C G A C T T C G G C G C G-D A B C Y L ~}$ \\ FAM-CGCGCATC $\overline{T T C A C A} G C G C G-D A B C Y L$ \\ Alexa Fluor 647-CACTCCGCTGCCTCCCGTAGGAGTG-BHQ1

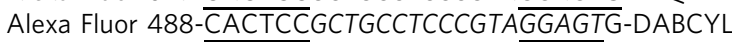 \\ Alexa Fluor 647- $\overline{C G G C G A} G C A A G T C G C T T C A C C T A C A T A T C G C C G-B H Q 1$ \\ CCGCCCCGCAGGTTCCCCTACGGCGG

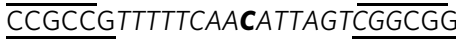

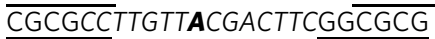 \\ AGTGGTAAGCGCCСTCC $\overline{C G A}$ \\ ACCCCAGTCATGAATCACAA \\ GCAGGTTCCCCTACGGTTA \\ TAAGGAGGTGATCCAACC
}

RNA nucleotides complementary to MB sequences are shown in italics, with methylated bases or bases whose methylation is catalyzed by MTase shown in bold italics. DNA nucleotides complementary to rRNA sequences are shown in italics, with nucleotides complementary to bases methylated by the relevant methyltransferase in bold italics. The self-complementary sections of Molecular Beacons that fold into the stem are underlined. The structures of modified nucleosides, fluorophores and quenchers are given in Supplementary Fig. 1

epitranscriptomic variation between cells and how methylation influences the spatial distribution of mRNA.

MR-FISH has distinct advantages and disadvantages compared with existing techniques. While the need for pre-existing knowledge of the locations of methylated bases to design methylation-sensitive probes and the finite multiplexing capacity of FISH make it unsuitable for transcriptome-wide discovery of base methylations, MR-FISH offers the ability to analyze methylation in large numbers of single cells, including heterogeneous populations and/or tissue samples. Alongside sequencing-based techniques that identify modifications ${ }^{17}$, and chemical probes that establish their structural effects ${ }^{34}$, MR-FISH promises to add another dimension to studies of methylated bases, by capturing cell-to-cell variation and potentially revealing the sub-cellular locations of specific methylated RNAs.

\section{Methods}

Materials. The E. coli strain BW25113 (parent strain) was purchased from ThermoFisher Scientific (Ulm, Germany). Three derivatives of this strain: JW00503 with specific deletion of the $k s g A$ gene $(\Delta k s g A)$; JW1181-1 with specific deletion of the $r r m A$ gene $(\Delta r r m A)$; and JW2913-1 with specific deletion of the $r s m E$ gene $(\Delta r s m E)$, were sourced from the Coli Genetic Stock Centre (Yale, USA) ${ }^{35}, 36$. Bacterial growth medium was purchased from Appleton Woods (Birmingham, $\mathrm{UK}$ ) and was prepared by dissolving in deionized water followed by autoclaving at $121^{\circ} \mathrm{C}$ for $20 \mathrm{~min}$. Phosphate-buffered saline (PBS) tablets, sodium chloride, tris (hydroxymethyl)aminomethane hydrochloride (Tris- $\mathrm{HCl}$ ), sodium dodecyl sulfate (SDS), diethyl pyrocarbonate (DEPC), formamide, benzamidine, phe-

nylmethylsulfonyl fluoride (PMSF), magnesium chloride, ammonium chloride, kanamycin, paraformaldehyde, 2-mercaptoethanol and sucrose were purchased from Sigma Aldrich (Gillingham, UK). The 125:24:1 phenol/chloroform/isoamyl alcohol mixture and chloroform were purchased from ThermoFisher Scientific (Paisley, UK). P1 nuclease, bacterial alkaline phosphatase, unmethylated nucleoside standards (A, C, G and U) were purchased from Sigma Aldrich, methylated nucleoside standards ( $N^{6}$-dimethyladenosine, 1-methylguanosine and 3-methyluridine) from Carbosynth (Compton, UK) and HPLC-grade solvents from VWR International Ltd (Lutterworth, UK). To avoid degradation of RNA, stock solutions of all buffer components (except formamide) for fluorescence melting and FISH were prepared using $0.1 \%$ DEPC to inactivate RNases and then autoclaved to decompose DEPC prior to use. All microcentrifuge tubes and pipette tips used were certified RNase free and bench surfaces cleaned with RNaseZAP ${ }^{\mathrm{TM}}$ according to the manufacturer's instructions (Sigma Aldrich). The sequences and code names of all oligonucleotides used in this work are given in Table 1, while structures of modified nucleosides, fluorophores and quenchers are given in Supplementary Fig. 1. RNA oligonucleotides (synthesized on the $1 \mu \mathrm{mol}$ scale and purified by denaturing polyacrylamide gel electrophoresis) were purchased from Dharmacon/GE Healthcare (Little Chalfont, UK); their identities were also confirmed by digestion to nucleosides followed by HPLC (Supplementary Fig. 3). Molecular Beacons (synthesized on the $0.2 \mu \mathrm{mol}$ scale and purified by double HPLC) were designed with the aid of the mfold and DINAMelt web servers ${ }^{37-39}$, and purchased from ATDBio (Southampton, UK). Unlabeled DNA oligonucleotides (synthesized on either 0.2 or $1 \mu \mathrm{mol}$ scale and purified by HPLC) were purchased from Sigma Aldrich. Lyophilized oligonucleotides received from the suppliers were dissolved in DEPC-treated deionized water to concentrations of $20-100 \mu \mathrm{M}$ as confirmed by $\mathrm{OD}_{260}$ (Nanodrop 2000, ThermoFisher Scientific) and aliquots stored at $-20^{\circ} \mathrm{C}$.

Thermodynamic characterization of methylation-sensitive Molecular Beacons. Fluorescence melting curves of Alexa-Fluor-488-labeled-methylation-sensitive probes (concentrations: $2.5 \mu \mathrm{M}$ (KsgA MB and RlmJ MB) or $2 \mu \mathrm{M}$ (RrmA MB and RsmE MB)) in the presence and absence of methylated and unmethylated RNA targets (concentrations: 0, 5, 10, 15, 20, 30 and $35 \mu \mathrm{M}$ (KsgA UM and KsgA $\mathrm{Me}$ ), or $0,25,30,35,40,45$ and $50 \mu \mathrm{M}$ (RrmA UM, RrmA Me, RsmE UM and RsmE Me), or $0,15,20,25,30,35$ and $40 \mu \mathrm{M}$ (RlmJ UM and RlmJ Me) in buffer ( $1 \times$ PBS (KsgA MB) or $1 \times$ PBS with $1 \mathrm{M} \mathrm{NaCl}$ (RrmA MB, RsmE MB and RlmJ $\mathrm{MB})$ ) were recorded using a Roche LightCycler ${ }^{\circledR} 480$, using the fluorescein filter set (exciting at $465 \mathrm{~nm}$ and measuring fluorescence at $510 \mathrm{~nm}$ ). Samples were prepared in a 96-well plate (LightCycler ${ }^{\circledR} 480$ Multiwell Plate 96, white, Roche, West Sussex, $\mathrm{UK}$ ) in a total volume of $20 \mu \mathrm{L}$. For experiments in the absence of RNA targets (i.e., Molecular Beacon only), samples were heated to $95^{\circ} \mathrm{C}$, held at this temperature for $10 \mathrm{~min}$, cooled from $95^{\circ} \mathrm{C}$ to $37^{\circ} \mathrm{C}$ at a rate of $1{ }^{\circ} \mathrm{C} \mathrm{min}-1$, held at $37^{\circ} \mathrm{C}$ for $10 \mathrm{~min}$ and heated from $37^{\circ} \mathrm{C}$ to $95^{\circ} \mathrm{C}$ at a rate of $1{ }^{\circ} \mathrm{C} \mathrm{min}-1$. For experiments in the presence of RNA targets, slower rates of heating/cooling were required to avoid hysteresis: samples were heated to $95^{\circ} \mathrm{C}$, held at this temperature for $10 \mathrm{~min}$ and then cooled in steps of $0.2^{\circ} \mathrm{C}$ at $0.5^{\circ} \mathrm{C} \mathrm{min}{ }^{-1}$ to $37^{\circ} \mathrm{C}$. Samples were then held at $37^{\circ} \mathrm{C}$ for $10 \mathrm{~min}$ before being heated to $95^{\circ} \mathrm{C}$, again in steps of $0.2^{\circ} \mathrm{C}$ at a rate of $0.5^{\circ} \mathrm{C} \mathrm{min}{ }^{-1}$. The fluorescence intensity was recorded for both the cooling (annealing) and heating (melting) phases and compared to confirm minimal hysteresis. Five technical replicates were performed under each condition.

Melting temperatures $\left(T_{\mathrm{b}}\right.$ or $\left.T_{\mathrm{d}}\right)$ were extracted using a script written in MATLAB. For each melting curve, an approximate first derivative was calculated, to which a single-term Gaussian function was fitted, with start and end points 
determined by user input and fit quality assessed by visual inspection. The center of the fitted Gaussian was taken to be the melting temperature.

The thermodynamics of hairpin melting (transition $2 \rightarrow 3$, Supplementary Fig. 2a) were analyzed as in Bonnet and $\mathrm{Tyagi}^{24}$, using the variation of fluorescence intensity with temperature (in the absence of target) to find the equilibrium constant at each temperature, using Eq. 1 (where $F$ is the fluorescence measured at a given temperature, $\alpha$ is the fluorescence of the hairpin structure (the fluorescence measured at $37^{\circ} \mathrm{C}$ ) and $\beta$ is the fluorescence of the random coil structure (fluorescence measured at $95^{\circ} \mathrm{C}$ ), Supplementary Fig. 2d).

$$
\begin{gathered}
K_{2-3}=\frac{F-\alpha}{\beta-F}, \\
R \ln \left(\frac{F-\alpha}{\beta-F}\right)=R \ln K_{2-3}=\Delta H_{2-3}^{\circ} \frac{1}{T}+\Delta S_{2-3}^{\circ} .
\end{gathered}
$$

The equilibrium constant in this form can be used to find the thermodynamic parameters for the transition, assuming no variation of thermodynamic parameters with temperature and no populated intermediates between the hairpin and random coil structures. A plot in the form of Eq. 2 (where $T$ is the temperature in K) was used to calculate the standard enthalpies $\left(\Delta H^{\circ}{ }_{2-3}\right.$ in $\left.\mathrm{J} \mathrm{mol}^{-1}\right)$ and entropies $\left(\Delta S^{\circ}{ }_{2-3}\right.$ in $\mathrm{J} \mathrm{mol}^{-1} \mathrm{~K}^{-1}$ ) of the hairpin melting transitions by linear fitting in Excel (Microsoft Corporation, Redmond, Washington, USA) or OriginPro (OriginLab Corporation, Northampton, Massachusetts, USA), and hence $\Delta G^{\circ}{ }_{2-3}$ (Supplementary Fig. 2e and g).

Thermodynamic parameters for the duplex to hairpin transition (transition $1 \rightarrow 2$, Supplementary Fig. 2a) were calculated as in Bonnet and Tyagi ${ }^{24}$. A plot in the form of Eq. 3 (where $R$ is the gas constant, $T_{0}$ is the target concentration, $B_{0}$ is the beacon concentration, $T_{\mathrm{d}}$ is the melting temperature for this transition) was used to calculate the standard enthalpies $\left(\Delta H^{\circ}{ }_{1-2}\right.$ in J mol $\left.{ }^{-1}\right)$ and entropies $\left(\Delta S^{\circ}{ }_{1-2}\right.$ in J mol $\left.{ }^{-1} \mathrm{~K}^{-1}\right)$ of the hairpin melting transitions by linear fitting in Excel or OriginPro (Supplementary Fig. $2 \mathrm{c}$ and $\mathrm{f}$ ).

$$
R \ln \left(T_{0}-0.5 B_{0}\right)=-\Delta H_{1-2}^{\circ} \frac{1}{T_{d}}+\Delta S_{1-2}^{\circ}
$$

Bacterial culture and fixation. Biological replicates were prepared by streaking a glycerol stock onto LB agar and individual colonies picked and cultured overnight at $37^{\circ} \mathrm{C}$ in LB broth, supplemented with kanamycin $\left(30 \mu \mathrm{g} \mathrm{mL}^{-1}\right)$ for growth JW0050-3 ( $\Delta$ ksgA), JW1181-1 ( $\Delta r r m A)$ and JW2913-1 ( $\Delta r s m E)$. The overnight culture was subsequently used as a $1 \%$ inoculum into fresh LB broth without antibiotics which was incubated at $37^{\circ} \mathrm{C}$ in an orbital shaker until the $\mathrm{OD}_{600}$ was $0.5-0.7$. One volume of $4 \%$ formaldehyde (freshly prepared from paraformaldehyde) in PBS (pH 6.9) was then added directly to bacterial culture $(7.5 \mathrm{~mL}$, approximately $4.5 \times 10^{9}$ colony-forming units) and the resulting suspension incubated at room temperature for $90 \mathrm{~min}$. Inactivated bacterial cells were then pelleted by centrifugation, washed three times in PBS $(10 \mathrm{~mL})$ and suspended in $50 \%$ ethanol/PBS $(1 \mathrm{~mL})$ yielding approximately $4.5 \times 10^{9}$ fixed cells per $\mathrm{mL}$, which were stored at $-20^{\circ} \mathrm{C}$ until required.

Bacterial co-culture and colony counting. Single colonies of BW25113 (parent strain) and JW0050-3 ( $\Delta k s g A)$ were picked and cultured separately overnight at $37^{\circ} \mathrm{C}$ in LB broth, without antibiotics. The overnight cultures were used to inoculate a single flask containing $100 \mathrm{~mL}$ of sterile LB broth without antibiotics to a starting $\mathrm{OD}_{600}$ of 0.005 absorbance units for each strain. The mixed culture was then incubated at $37^{\circ} \mathrm{C}$ in an orbital shaker until the $\mathrm{OD}_{600}$ was $0.5-0.7$, at which point $7.5 \mathrm{~mL}$ of culture was removed and fixed as described above. The ratio of parent/ $\Delta \mathrm{ksgA}$ was determined by diluting the culture by a factor of $10^{6}$ in sterile LB broth and spreading $200 \mu \mathrm{L}$ onto LB agar plates with or without $30 \mu \mathrm{g} \mathrm{mL}^{-1}$ kanamycin. Colonies were counted after $18 \mathrm{~h}$ of incubation at $37^{\circ} \mathrm{C}$.

$16 S$ ribosomal RNA purification. Single colonies BW25113 (parent strain) and JW0050-3 ( $\triangle \mathrm{ksgA}$ ) were picked and grown overnight at $37^{\circ} \mathrm{C}$ in LB broth, supplemented with kanamycin $\left(50 \mu \mathrm{g} \mathrm{mL}^{-1}\right)$ for growth of the $\Delta k s g A$ strain. The overnight culture was used as a $1 \%$ inoculum into pre-warmed LB medium $(4 \times$ $1000 \mathrm{~mL}$ in $2 \mathrm{~L}$ flasks) and cultured without antibiotics until the $\mathrm{OD}_{600}$ was $0.5-0.6$. The cells were harvested and pellets washed twice by resuspension in PBS $(50 \mathrm{~mL})$, prior to being flash-frozen for storage at $-80^{\circ} \mathrm{C}$. The ribosome purification protocol was modified from a previously published method ${ }^{40}$. All buffers were supplemented with $0.1 \mathrm{mM}$ benzamidine and $1 \mathrm{mM}$ PMSF directly before use. Cell pellets were thawed on ice, resuspended in $15 \mathrm{~mL}$ buffer C (20 mM Tris pH 7.5, 10 $\mathrm{mM} \mathrm{MgCl}_{2}, 200 \mathrm{mM} \mathrm{NH}_{4} \mathrm{Cl}, 6 \mathrm{mM} 2$-mercaptoethanol) and lysed using an Emulsiflex-C3 homogenizer (Avestin, CAN). The resulting lysate was cleared by pelleting debris twice for $30 \mathrm{~min}$ at $30,000 \times \mathrm{g}$ at $4{ }^{\circ} \mathrm{C}$ in an $\mathrm{F} 21-8 \times 50 \mathrm{y}$ rotor (Thermo Fisher). The resulting supernatant was layered on a $40 \mathrm{~mL}$ sucrose cushion (buffer $\mathrm{C}$ adjusted to $500 \mathrm{mM} \mathrm{NH}_{4} \mathrm{Cl}, 1.1 \mathrm{M}$ sucrose) and ribosomes pelleted for $18 \mathrm{~h}$ at $142,000 \times g$ at $4^{\circ} \mathrm{C}$ in a $45 \mathrm{TI}$ rotor (Beckman Coulter). Pellets were washed twice and resuspended for $1 \mathrm{~h}$ under gentle agitation in $1 \mathrm{~mL}$ buffer $\mathrm{D}$ (buffer $\mathrm{C}$ adjusted to $1 \mathrm{M} \mathrm{NH}_{4} \mathrm{Cl}$ ). In order to separate the $70 \mathrm{~S}$ ribosomes into $30 \mathrm{~S}$ and $50 \mathrm{~S}$ subunits, the samples were dialyzed overnight at $4{ }^{\circ} \mathrm{C}$ against $20 \mathrm{mM}$ Tris
pH 7.5, $1 \mathrm{mM} \mathrm{MgCl} 2,200 \mathrm{mM} \mathrm{NH}_{4} \mathrm{Cl}, 6 \mathrm{mM}$ 2-mercaptoethanol. Six 10-30\% sucrose gradients in buffer D were prepared for each sample, using a Gradient Station IP (Biocomp, USA). Each gradient was prepared in advance, layered with $100-150 \mu \mathrm{L}$ of sample $\left(\sim 150 \mathrm{~A}_{260}\right.$ units) and spun at $58,200 \times \mathrm{g}$ in a SW28 rotor (Beckman Coulter) for $18 \mathrm{~h}$ at $4{ }^{\circ} \mathrm{C}$. Fractions corresponding to the 30S and 50S subunits were separately diluted to $60 \mathrm{~mL}$ in buffer $\mathrm{C}$ and pelleted for $18 \mathrm{~h}$ at $142,000 \times g$ at $4{ }^{\circ} \mathrm{C}$ in a TI 45 rotor. The pellets were resuspended in $250 \mu \mathrm{L}$ RNasefree water and flash-frozen for storage. Purified $30 \mathrm{~S}$ ribosomal subunits were washed twice with 1 vol. of 125:24:1 phenol/chloroform/isoamyl alcohol pH 4.5 followed by once with $1 \mathrm{vol}$. chloroform. RNA was ethanol precipitated by adding 0.1 vol. of $3 \mathrm{M}$ sodium acetate followed by $2 \mathrm{vol}$. of ice-cold ethanol and pelleted by centrifugation in a bench top microcentrifuge ( $10 \mathrm{~min}$, maximum speed). The RNA was dissolved in water $(40 \mu \mathrm{L})$ and used immediately in RNase digestion reactions.

RNase digestion. Purified rRNA (9-50 $\mathrm{ng} \mu \mathrm{L}^{-1}$ ) or synthetic oligonucleotides (25 $\mu \mathrm{M})$ were dissolved in water. Digestion reactions were prepared by addition of ammonium acetate buffer $(20 \mathrm{mM}, \mathrm{pH}$ 7) and $\mathrm{P} 1$ nuclease $(0.5 \mathrm{U})$, followed by incubation at $45^{\circ} \mathrm{C}$ for $4 \mathrm{~h}$. The reaction was then cooled to room temperature, bacterial alkaline phosphatase $(150 \mathrm{U})$ added followed by incubation at $37^{\circ} \mathrm{C}$ for a further $2 \mathrm{~h}$. Proteins were precipitated by addition of perchloric acid ( $1 \%$ final vol.) and pelleted by centrifugation (20 min, maximum speed). Supernatants were immediately analyzed by HPLC.

HPLC analysis. A fully automated Shimadzu Prominence platform, operated through LabSolutions software, was used for all HPLC analyses. The platform consisted of a LC-20AD ternary, low-pressure mixing solvent delivery system with a DGU-20A inline degasser, SIL-20AHT variable volume auto-injector and autosampler, SPD-M20A diode array detector and CTD-10ASVP heated column oven. HPLC-grade solvents were used for preparing the mobile phase. Peaks were identified by comparing their retention times with standards prepared from commercially sourced nucleosides. For analysis of digested and undigested synthetic RNA oligonucleotides, the HPLC conditions shown in Table 2 were used. For nucleoside quantification in digested samples, the integrated peak area was compared to a dilution series prepared from commercially sourced nucleosides. For analysis of digested $16 \mathrm{~S}$ ribosomal RNA, the HPLC conditions shown in Table 3 were used.

Fluorescence in situ hybridization. The protocol for FISH was adapted from Valm et al. ${ }^{41}$. Fixed $E$. coli cells were first washed with wash buffer A $(0.9 \mathrm{M} \mathrm{NaCl}$, $0.02 \mathrm{M}$ Tris, $\mathrm{pH} 7.5,0.01 \%$ SDS and $20 \% \mathrm{v} / \mathrm{v}$ formamide) and then resuspended at $6.75 \times 10^{6}$ cells per $\mu \mathrm{L}$ in $20 \mu \mathrm{L}$ hybridization buffer $(0.9 \mathrm{M} \mathrm{NaCl}, 0.02 \mathrm{M}$ Tris, $\mathrm{pH}$ $7.5,0.01 \%$ SDS, formamide $(20 \% \mathrm{v} / \mathrm{v}$ for detecting KsgA and RrmA modifications, $30 \% \mathrm{v} / \mathrm{v}$ for detecting RsmE modification), Alexa-Fluor-647-labeled-methylationinsensitive Molecular Beacon ( $1 \mu \mathrm{M}$ 16S MB for detecting KsgA and RsmE modifications, $1 \mu \mathrm{M} 23 \mathrm{~S} \mathrm{MB}$ for detecting RrmA modification), Alexa-Fluor-488labeled-methylation-sensitive Molecular Beacon $(1 \mu \mathrm{M}$ KsgA MB, $1 \mu \mathrm{M}$ RrmA MB or $2 \mu \mathrm{M}$ RsmE MB); unlabeled helper oligonucleotides that bind to rRNA, adjacent to the methylation-sensitive probe, were included for detection of RsmE modification ( $2 \mu \mathrm{M}$ HLP1, HLP2, HLP3 and HLP4); for experiments to test whether green fluorescence results from hybridization (Supplementary Fig. 10), unlabeled

\section{Table 2 HPLC conditions for analysis of digested and undigested synthetic RNA oligonucleotides}

\section{Column: Waters XSelect HSS T3, $100 \AA$, $3.5 \mu \mathrm{m}, 3.0 \times 150 \mathrm{~mm}$}

\section{Column temperature: $30^{\circ} \mathrm{C}$}

Flow rate: $0.7 \mathrm{~mL} \mathrm{~min}-1$

Injection volume: $8 \mu \mathrm{L}$

Step Mobile phase composition / \%

time / $\min$

A B C $\left(0.2 \mathrm{M} \mathrm{NH}_{4} \mathrm{OAc}\right.$,

\begin{tabular}{llll} 
& (water) & (acetonitrile) & $\mathbf{p H ~ 6 , ~ 2 5 \% ~ a c e t o n i t r i l e ) ~}$ \\
\hline 0 & 89 & 1 & 10 \\
2.5 & 89 & 1 & 10 \\
5.5 & 80 & 10 & 10 \\
10 & 40 & 50 & 10 \\
10.1 & 10 & 80 & 10 \\
11 & 10 & 80 & 10 \\
11.1 & 89 & 1 & 10 \\
20 & 89 & 1 & 10
\end{tabular}


Table 3 HPLC conditions for analysis of digested ribosomal RNA

Column: Waters XSelect HSS T3, $100 \AA$, $3.5 \mu \mathrm{m}, 3.0 \times 150 \mathrm{~mm}$

Column temperature: $30^{\circ} \mathrm{C}$

Flow rate: $0.7 \mathrm{~mL} \mathrm{~min}^{-1}$

Injection volume: $8 \mu \mathrm{L}$

Step time Mobile phase composition / \%

/ $\min$

\begin{tabular}{|c|c|c|c|}
\hline & $\begin{array}{l}\text { A } \\
\text { (water) }\end{array}$ & $\begin{array}{l}\text { B } \\
\text { (acetonitrile) }\end{array}$ & $\begin{array}{l}\mathrm{C}\left(0.2 \mathrm{M} \mathrm{NH}_{4} \mathrm{OAc}, \mathrm{pH} 6,\right. \\
2.5 \% \text { acetonitrile })\end{array}$ \\
\hline 0 & 90 & 0 & 10 \\
\hline 3.6 & 90 & 0 & 10 \\
\hline 6.0 & 88 & 2 & 10 \\
\hline 7.5 & 85 & 5 & 10 \\
\hline 13.5 & 70 & 20 & 10 \\
\hline 24 & 55 & 35 & 10 \\
\hline 27.5 & 10 & 80 & 10 \\
\hline 28.8 & 10 & 80 & 10 \\
\hline 29.0 & 90 & 0 & 10 \\
\hline 38.0 & 90 & 0 & 10 \\
\hline
\end{tabular}

Molecular Beacons were added (10 $\mu \mathrm{M}$ KsgA BLK, $10 \mu \mathrm{M}$ RrmA BLK or $20 \mu \mathrm{M}$ RsmE BLK)). For three-color multiplexed detection of KsgA and RrmA methylations, the hybridization buffer contained Alexa-Fluor-647-labeled-methylationsensitive Molecular Beacon (1 $\mu \mathrm{M} 23 \mathrm{~S} \mathrm{MB})$ and two methylation-sensitive Molecular Beacons $(1 \mu \mathrm{M}$ Alexa-Fluor-488-labeled KsgA MB and $1 \mu \mathrm{M}$ RrmA MB-

Cy3). To assess the influence of hybridization stoichiometry on cell-to-cell variation of the two-color ratio (Supplementary Fig. 6), hybridization buffer containing two methylation-insensitive Molecular Beacons was used ( $1 \mu \mathrm{M}$ Alexa-Fluor-647labeled 16S MB and $1 \mu \mathrm{M}$ Alexa-Fluor-488-labeled 16S MB-G). Samples were incubated at $37^{\circ} \mathrm{C}$ for the appropriate length of time $(0.5,1,2,3,4.5,6,11,16$ or $21 \mathrm{~h}$ for the timecourse data shown in Supplementary Fig. 5, $21 \mathrm{~h}$ for all other experiments detecting KsgA and RrmA modifications and $18 \mathrm{~h}$ for detection of RsmE modification) with agitation at $200 \mathrm{rpm}$. Cells were then washed at $37^{\circ} \mathrm{C}$ with agitation at $200 \mathrm{rpm}$ in $30 \mu \mathrm{L}$ wash buffer A for $15 \mathrm{~min}, 30 \mu \mathrm{L}$ wash buffer B $(0.9 \mathrm{M} \mathrm{NaCl}, 0.02 \mathrm{M}$ Tris, $\mathrm{pH} 7.5,0.01 \%$ SDS $)$ for $15 \mathrm{~min}$ and then resuspended in $10 \mu \mathrm{L}$ imaging buffer $(0.025 \mathrm{M} \mathrm{NaCl}, 0.02 \mathrm{M}$ Tris, $\mathrm{pH}$ 7.5). Then, $5 \mu \mathrm{L}$ of this cell suspension was added to a coverslip $(22 \times 22 \mathrm{~mm}$, thickness $0.13-0.17 \mathrm{~mm}$, Menzel Gläser, pre-cleaned with argon plasma for at least $30 \mathrm{~min}$ (Femto Plasma Cleaner; Diener Electronic, Royal Oak, MI, USA) and subsequently attached to a Frame-Seal slide chamber $(9 \times 9 \mathrm{~mm}$, Biorad, Hercules, CA, USA $))$, and a drop of mounting medium (Hydromount slide mounting medium, Fisher Scientific) was applied. Samples were then sealed with another plasma-cleaned coverslip and allowed to set for at least $30 \mathrm{~min}$ at room temperature before imaging.

Fluorescence microscopy. Two-color fluorescence images except those used to generate Supplementary Fig. 6 were acquired using a microscope previously described ${ }^{42}$. A HeNe laser $(633 \mathrm{~nm}, 10 \mathrm{~mW}, 25$-LHP-991-230, Melles Griot, Carlsbad, USA) and a diode laser operating at $488 \mathrm{~nm}(20 \mathrm{~mW}$, PC13589, Cyan Scientific, Spectra Physics, Santa Clara, USA) were directed into an objective lens (Plan Fluor 20x air, numerical aperture (NA) 0.50, Nikon for all data except those in Supplementary Fig. 13, where two other objectives were used for comparison: CFI Plan Apochromat $\lambda$ 40× air, NA 0.95 and $60 \times$ Plan Apo TIRF oil immersion, NA 1.45, both by Nikon) mounted on an Eclipse TE2000-U microscope (Nikon), parallel to the optical axis in epifluorescence mode. Emitted fluorescence was collected by the same objective and separated from excitation light by a dichroic mirror (FF500/646-DiO1; Semrock, Rochester, USA). Green and red fluorescence were separated from each other and filtered by a second dichroic mirror and filter sets (FF605-Di02, Roper Scientific, USA, FF03-525/50-25 (green emission), BLP01635R-25 (red emission), all from Semrock), mounted on a Dual-View imaging system (Photometrics, Tucson, USA). Fluorescence emission was recorded on an EMCCD camera (Cascade II:512, Photometrics), cooled to $-70^{\circ} \mathrm{C}$; each color was recorded on a separate half of the chip. Data (30-100 images per sample) were acquired in grids of four or five successive images (separated by $200 \mu \mathrm{m}$ for images acquired using the $20 \times$ objective and $90 \mu \mathrm{m}$ for images acquired using the $40 \times$ and $60 \times$ objectives), first under $633 \mathrm{~nm}$ illumination (with exposure times of $200 \mathrm{~ms}$ for KsgA data, $200 \mathrm{~ms}$ for RrmA data and $200 \mathrm{~ms}$ (20× objective), $50 \mathrm{~ms}$ (40× objective) or $25 \mathrm{~ms}(60 \times$ objective) for RsmE data), then under $488 \mathrm{~nm}$ illumination (with exposure times of $200 \mathrm{~ms}$ for KsgA data, $600 \mathrm{~ms}$ for RrmA data and $200 \mathrm{~ms}$ $(20 \times), 50 \mathrm{~ms}(40 \times)$ or $25 \mathrm{~ms}(60 \times)$ for RsmE data) using a motorized stage (Optiscan system, Prior Scientific, Cambridge, UK), controlled with
Micromanager $^{43}$. Out-of-focus images were discarded during acquisition, i.e., before analysis.

Three-color fluorescence images for multiplexed detection of methylations (Fig. 4 and Supplementary Fig. 11) and two-color images used to generate Supplementary Fig. 6 were acquired using another home-built microscope. The output from three lasers operating at $488 \mathrm{~nm}$ (Toptica, iBeam smart, $200 \mathrm{~mW}$, Munich, Germany), $561 \mathrm{~nm}$ (Cobalt Jive, $200 \mathrm{~mW}$, Cobalt, Sweden) and $640 \mathrm{~nm}$ (Coherent Cube, $100 \mathrm{~mW}$, Coherent, USA) were attenuated using neutral density filters, and passed through quarter-wave plates, beam expanders and their respective excitation filters (LL01-488-25 for $488 \mathrm{~nm}$ FF01-561/14-25 for $561 \mathrm{~nm}$ and FF01-640/14-25 for $640 \mathrm{~nm}$; Semrock). The lasers were combined using two dichroic mirrors (FF552-Di02-25×36, FF458-Di02-25×36, Semrock), and passed through the back port of a Nikon Ti-E Eclipse microscope (Nikon, Japan), where they were reflected down the optical axis of a $1.49 \mathrm{NA}, 60 \times$ TIRF objective (UPLSAPO, 60XO TIRF, Olympus) in epifluorescence mode. Then, 641, 561 and $488 \mathrm{~nm}$ excitation was performed sequentially, and emitted fluorescence was collected by the same objective and separated from excitation light by a dichroic mirror (Di01-R405/488/561/635-25×36, Semrock). The red, yellow and green fluorescence emissions were filtered by further bandpass and/or longpass filters (BLP01-635R-25 (red emission), LP02-568RS-25 and FF01-587/35-25 (yellow emission), BLP01-488R-25 (green emission); Semrock) before being passed through a $2.5 \times$ beam expander and recorded on an EMCCD camera (Delta Evolve 512, Photometrics, AZ, USA) operating in frame transfer mode (EMGain of $11.5 \mathrm{e}^{-1}$ per ADU and $250 \mathrm{ADU}$ per photon). Each pixel corresponded to a length of $131.5 \mathrm{~nm}$. Data (100 images per sample) were acquired in grids of 10 by 10 successive images (separated by $100 \mu \mathrm{m}$ ), using a motorized stage (Proscan III system, Prior Scientific, Cambridge, UK), controlled with Micromanager ${ }^{43}$. Two-color images were first acquired under $640 \mathrm{~nm}$ illumination (with an exposure time of $10 \mathrm{~ms}$ ), then under $488 \mathrm{~nm}$ illumination (with an exposure time of $40 \mathrm{~ms}$ ), while three-color images were first acquired under $640 \mathrm{~nm}$ illumination (with an exposure time of $10 \mathrm{~ms}$ ), then under $561 \mathrm{~nm}$ illumination (with an exposure time of $20 \mathrm{~ms}$ ), and then under $488 \mathrm{~nm}$ illumination (with an exposure time of $10 \mathrm{~ms}$ ). The microscope was fitted with a perfect focus system which auto-corrects the $z$ stage drift during a prolonged period of imaging. Out-of-focus images were discarded during acquisition, i.e., before analysis.

Image analysis. Bacteria detection (identifying regions of interest for analysis): Fluorescence images were analyzed using custom software written in MATLAB (MATLAB R2010b, The MathWorks, Inc., Supplementary Software). For each field of view, two or three images are acquired sequentially for each color channel, exciting the red ('red image') and then green ('green image') fluorophore, and, in the case of three-color imaging, the Cy3 fluorophore ('yellow image'). The process therefore begins with a step to ensure good registration across the image pairs or triplets. To achieve this, a sub-region is defined in the red image and the normalized two-dimensional cross-correlation coefficients are calculated between this sub-region and the yellow or the green image, from which the $x y$ position of maximal cross-correlation can be obtained for each image. The difference between the positions found gives the offset between the green or yellow channel from the red. In some instances, calculation of the cross-correlation does not return realistic values, in particular if the intensities are low or there are few image features. In this case, the offset is set to the median offset found for images of the given data set. The image of one channel is then shifted with respect to the other channel by this offset value, correcting for translational shift.

Prior to the detection of stained bacteria, which appear as local regions of high intensity above baseline levels in fixed positions within the field of view (Supplementary Fig. 4), the red image is converted to a binary image (mask) using a threshold intensity set to be the mean single pixel intensity of the bandpassfiltered red image plus 20 times this value. Pixels with intensity values below the threshold are set to zero and considered to be background, while pixels with values above the threshold are set to one and potential candidates for bacteria signals. This threshold was determined empirically and by visual inspection of the resulting mask and comparison with the original data. Only the signal from the red channel is used for bacteria detection to minimize any selection bias due to the expected large variation in fluorescence brightness in the green and yellow channels. For example, bacteria with highly methylated ribosomes might not give rise to sufficient intensity in the green channel to be detected, biasing detection toward bacteria with low ribosomal methylation state.

Selection of the signals from single, isolated bacteria: In the next step, objects (bacteria) are detected by tracing continuous regions of ones in the binary image (mask). It is necessary to include further selection criteria in the algorithm for robust discrimination against aggregates of bacteria which may consist of bacteria belonging to different strains. To this end, for each region, the position, size and continuity (number of pixels corresponding to "holes" with value zero in the region) is determined. Signals are assumed to correspond to single bacteria if the area of the region is $1-10 \mu \mathrm{m}^{2}$ and contains $<50$ background pixels (value zero). Selection criteria based on region ellipticity were also explored but not found to improve discrimination. For regions that fulfill these requirements (single bacteria), the mean intensity for the region is calculated from the green, yellow and red original images and corrected for the local background by subtracting the average intensity of 
a shell around the detected region $(+/-3 \mathrm{px})$. The entire procedure is fully automated and does not require the user to select control areas or individual bacteria.

Analysis and presentation of the extracted data: Finally, the ratio of red/green intensity (or yellow/green in the case of three-color experiments) was calculated for each bacterium. Since the distribution of the two-color ratio for a single population is expected to be log-normal, the histograms were plotted logarithmically and fitted to a single-term Gaussian function, thus obtaining the center of each ratio distribution. All plots and further fits were created in OriginPro.

Code availability. MATLAB code for analyzing MR-FISH image data is available at https://github.com/kganzinger/Analysis-Software-for-in-situ-hybridizationdata-in-single-cells. The code requires MATLAB R2010b (or later releases) and the following tool boxes to run: Image Processing, Curve Fitting and Statistics.

Statistics. Sufficient imaging data were collected to yield $>450$ cells per sample for analysis after thresholding, with three to seven replicate samples per experiment (with $n$ quoted in the appropriate figure legends). Descriptive statistics are used throughout.

Data availability. All imaging data used to produce the main text figures and supplementary figures, as well as Excel source data for main text Figs. 1-4 are deposited on figshare ${ }^{44}$. HPLC and thermal melting data are available on reasonable request.

Received: 10 March 2017 Accepted: 20 December 2017

Published online: 13 February 2018

\section{References}

1. Starr, J. L. \& Fefferman, R. The occurrence of methylated bases in ribosomal ribonucleic acid of Escherichia coli K12 W-6. J. Biol. Chem. 239, 3457-3461 (1964).

2. Machnicka, M. A. et al. MODOMICS: A database of RNA modification pathways - 2013 update. Nucleic Acids Res. 41, 1-6 (2013).

3. Wilson, D. N. Ribosome-targeting antibiotics and mechanisms of bacterial resistance. Nat. Rev. Microbiol. 12, 35-48 (2014).

4. Lai, C. J. \& Weisblum, B. Altered methylation of ribosomal RNA in an erythromycin-resistant strain of Staphylococcus aureus. Proc. Natl. Acad. Sci. USA 68, 856-860 (1971)

5. Giessing, A. M. B. et al. Identification of 8-methyladenosine as the modification catalyzed by the radical SAM methyltransferase Cfr that confers antibiotic resistance in bacteria. RNA 15, 327-336 (2009).

6. Björk, G. R., Wikström, P. M. \& Byström, A. S. Prevention of translational frameshifting by the modified nucleoside 1-methylguanosine. Science $\mathbf{2 4 4}$, 986-989 (1989).

7. Jia, G. et al. N6-Methyladenosine in nuclear RNA is a major substrate of the obesity-associated FTO. Nat. Chem. Biol. 7, 885-887 (2011).

8. Jia, G. et al. Oxidative demethylation of 3-methylthymine and 3-methyluracil in single-stranded DNA and RNA by mouse and human FTO. FEBS Lett. 582, 3313-3319 (2008).

9. Dominissini, D. et al. Topology of the human and mouse m6A RNA methylomes revealed by m6A-seq. Nature 485, 201-206 (2012).

10. Meyer, K. D. et al. Comprehensive analysis of mRNA methylation reveals enrichment in 3' UTRs and near stop codons. Cell 149, 1635-1646 (2012).

11. Dominissini, D. et al. The dynamic N1-methyladenosine methylome in eukaryotic messenger RNA. Nature 530, 441-446 (2016).

12. Li, X. et al. Transcriptome-wide mapping reveals reversible and dynamic N1methyladenosine methylome. Nat. Chem. Biol. 12, 311-316 (2016).

13. Mauer, J. et al. Reversible methylation of m6Am in the $5^{\prime}$ cap controls mRNA stability. Nature 541, 371-375 (2016).

14. He, C. Grand challenge commentary: RNA epigenetics? Nat. Chem. Biol. 6, 863-865 (2010).

15. Kellner, S., Burhenne, J. \& Helm, M. Detection of RNA modifications. RNA Biol. 7, 237-247 (2010).

16. Motorin, Y., Muller, S., Behm-Ansmant, I. \& Branlant, C. Identification of modified residues in RNAs by reverse transcription-based methods. Methods Enzymol. 425, 21-53 (2007).

17. Dominissini, D., Moshitch-Moshkovitz, S., Salmon-Divon, M., Amariglio, N. \& Rechavi, G. Transcriptome-wide mapping of N(6)-methyladenosine by $\mathrm{m}(6)$ A-seq based on immunocapturing and massively parallel sequencing. Nat. Protoc. 8, 176-189 (2013).

18. Raj, A., van den Bogaard, P., Rifkin, S. A., van Oudenaarden, A. \& Tyagi, S. Imaging individual mRNA molecules using multiple singly labeled probes. Nat. Methods 5, 877-879 (2008).

19. Taniguchi, Y. et al. Quantifying E. coli proteome and transcriptome with singlemolecule sensitivity in single cells. Science 329, 533-538 (2010).
20. Chen, K. H., Boettiger, A. N., Moffitt, J. R., Wang, S. \& Zhuang, X. Spatially resolved, highly multiplexed RNA profiling in single cells. Science 348, aa6690 (2015).

21. Micura, R. et al. Methylation of the nucleobases in RNA oligonucleotides mediates duplex-hairpin conversion. Nucleic Acids Res. 29, 3997-4005 (2001).

22. Roost, C. et al. Structure and thermodynamics of N 6 -methyladenosine in RNA: a spring-loaded base modification. J. Am. Chem. Soc. 137, 2107-2115 (2015).

23. Tyagi, S. \& Kramer, F. R. Molecular beacons: probes that fluoresce upon hybridization. Nat. Biotechnol. 14, 303-308 (1996).

24. Bonnet, G. \& Tyagi, S. Thermodynamic basis of the enhanced specificity of structured DNA probes. Proc. Natl. Acad. Sci. USA 96, 6171-6176 (1999).

25. Demirci, H. et al. Modification of $16 \mathrm{~S}$ ribosomal RNA by the KsgA methyltransferase restructures the $30 \mathrm{~S}$ subunit to optimize ribosome function. RNA 16, 2319-2324 (2010).

26. Helser, T. L., Davies, J. E. \& Dahlberg, J. E. Change in methylation of $16 \mathrm{~S}$ ribosomal RNA associated with mutation to kasugamycin resistance in Escherichia coli. Nat. New Biol. 233, 12-14 (1971).

27. Gustafsson, C. \& Persson, B. C. Identification of the rrmA gene encoding the 23S rRNA m1G745 methyltransferase in Escherichia coli and characterization of an m1G745- deficient mutant. J. Bacteriol. 180, 359-365 (1998).

28. Basturea, G. N., Rudd, K. E. \& Deutscher, M. P. Identification and characterization of RsmE, the founding member of a new RNA base methyltransferase family. $R N A 12,426-434$ (2006).

29. Zhou, H. et al. m1A and $\mathrm{m} 1 \mathrm{G}$ disrupt A-RNA structure through the intrinsic instability of Hoogsteen base pairs. Nat. Struct. Mol. Biol. 23, 803-810 (2016)

30. Dennis, P. P. \& Bremer, H. Modulation of chemical composition and other parameters of the cell at different exponential growth rates. EcoSal Plus 3, doi:10.1128/ecosal.5.2.3 (2008).

31. Dong, H., Nilsson, L. \& Kurland, C. G. Co-variation of tRNA abundance and codon usage in Escherichia coli at different growth rates. J. Mol. Biol. 260, 649-663 (1996).

32. Zenklusen, D., Larson, D. R. \& Singer, R. H. Single-RNA counting reveals alternative modes of gene expression in yeast. Nat. Struct. Mol. Biol. 15, 1263-1271 (2008).

33. Marinov, G. K. et al. From single-cell to cell-pool transcriptomes: stochasticity in gene expression and RNA splicing. Genome Res. 24, 496-510 (2014).

34. Spitale, R. C. et al. RNA SHAPE analysis in living cells. Nat. Chem. Biol. 9, 18-20 (2013).

35. E. coli Genetic Resources at Yale CGSC, The Coli Genetic Stock Center. Available at: http://cgsc2.biology.yale.edu/index.php.

36. Baba, T. et al. Construction of Escherichia coli K-12 in-frame, single-gene knockout mutants: the Keio collection. Mol. Syst. Biol. 2, 2006.0008 (2006).

37. The UNAFold Web Server. Available at: http://unafold.rna.albany.edu.

38. Zuker, M. Mfold web server for nucleic acid folding and hybridization prediction. Nucleic Acids Res. 31, 3406-3415 (2003).

39. Markham, N. R. \& Zuker, M. DINAMelt web server for nucleic acid melting prediction. Nucleic Acids Res. 33, W577-W581 (2005).

40. Brown, A., Fernández, I. S., Gordiyenko, Y. \& Ramakrishnan, V. Ribosomedependent activation of stringent control. Nature 534, 277-280 (2016).

41. Valm, A. M. et al. Systems-level analysis of microbial community organization through combinatorial labeling and spectral imaging. Proc. Natl. Acad. Sci. USA 108, 4152-4157 (2011)

42. Ganzinger, K. A. et al. Single-molecule imaging reveals that small amyloid- $\beta 1-$ 42 oligomers interact with the cellular prion protein $(\mathrm{PrPc})$. Chembiochem 15, 2515-2521 (2014).

43. Edelstein, A. D. et al. Advanced methods of microscope control using $\mu$ Manager software. J. Biol. Methods 1, 10 (2014).

44. Ranasinghe, R. T. et al. Detecting RNA base methylations in single cells by in situ hybridization (datasets). https://doi.org/10.6084/m9.figshare.4667959.v1.

\section{Acknowledgements}

We thank Professor Peter L. Roach (University of Southampton) and Dr. Paul R. Race (University of Bristol) for their critical reading of the manuscript. This work was supported by the EU Innovative Medicines Initiative, IMI (RAPP-ID project, grant agreement, no. 115153), the UK Biotechnology and Biological Sciences Research Council, BBSRC (Project Grant: BB/J017906/1) and the UK Engineering and Physical Sciences Research Council, EPRSC (Project Grant: EP/M027546/1). M.H.H. was supported by a Junior Research Fellowship at Christ's College, University of Cambridge, and the Herchel Smith Foundation. J.W.C. and W.H.S. were supported by the Medical Research Council, UK (MC_U105181009 and MC_UP_A024_1008). D.K. is supported by the Royal Society.

\section{Author contributions}

R.T.R. and M.R.C. conceived the MR-FISH approach. R.T.R., M.R.C., K.A.G., J.S. and D. K. designed experiments. B.W.L., C.S. and R.T.R. collected fluorescence melting data. R. T.R. and M.H.H. collected microscopy data. M.R.C. collected biochemical and microbiological data. R.T.R. and K.A.G. designed analysis software. K.A.G. wrote analysis 
software. M.R.C., W.H.S., N.S. and J.W.C. contributed materials. R.T.R., M.R.C., K.A.G., B.W.L. and C.S. analyzed data. R.T.R., M.R.C., K.A.G., J.S. and D.K. wrote the paper.

\section{Additional information}

Supplementary Information accompanies this paper at https://doi.org/10.1038/s41467017-02714-7.

Competing interests: The authors declare no competing financial interests.

Reprints and permission information is available online at http://npg.nature.com/ reprintsandpermissions/

Publisher's note: Springer Nature remains neutral with regard to jurisdictional claims in published maps and institutional affiliations. (c) (i) Open Access This article is licensed under a Creative Commons Attribution 4.0 International License, which permits use, sharing, adaptation, distribution and reproduction in any medium or format, as long as you give appropriate credit to the original author(s) and the source, provide a link to the Creative Commons license, and indicate if changes were made. The images or other third party material in this article are included in the article's Creative Commons license, unless indicated otherwise in a credit line to the material. If material is not included in the article's Creative Commons license and your intended use is not permitted by statutory regulation or exceeds the permitted use, you will need to obtain permission directly from the copyright holder. To view a copy of this license, visit http://creativecommons.org/ licenses/by/4.0/.

(C) The Author(s) 2018 